\title{
FACIAL RECOGNITON BASED DOOR LOCKING AND UNLOCKING MECHANISM BASED ON IOT
}

\author{
Purobi Parasar, Hirockjyoti Deka, Bishal Saikia, Nilabh Anjan Chutia \\ School of Computing Science, Assam Kaziranga University, Jorhat, India \\ Dr. Purnendu Bikash Acharjee \\ Assistant Professor/Associate Dean, \\ School of Computer Science, Assam Kaziranga University, Jorhat
}

\begin{abstract}
Now a days Security Has Become an Important Issue to Be Resolved. So, We Are Solving That Matter by Using Updated Technology. This Project "Face Recognition Based Door Unlocking System" deals with The Conception to Protect Locking Mechanism Utilizing IoT for Door Unlocking Process to Give Essential Security to Our House, Bank Lockers and others. In This Project We Look into the Accuracy of The Face Recognition Algorithms Using OpenCV And Python Computer Language. Local Binary Pattern Histogram Algorithm Is Used for Face Recognition. Training and Identification Is Done in Raspberry pi.
\end{abstract}

Keyword: Face recognition, Internet of things (IoT), Local binary pattern histogram (LBPH), Raspberry pi.

\section{INTRODUCTION}

In biometrics security, the face is commonly used for recognizing people. In today's day and age face recognition received much needed attention due to its application found in security, forensic, face tracking, criminal detection etc. The face recognition process is performed by capturing a picture of the visitants and differentiate it with the stored databases. Bio metric is a challenging field, and face biometric is no exception. There are various limitations associated with face Biometrics such as illumination, head poses, facial expressions, ageing etc. Automatic face recognition involves features extraction and face recognition, face detection, face algorithms are classified into two classes based on geometric features and image template.

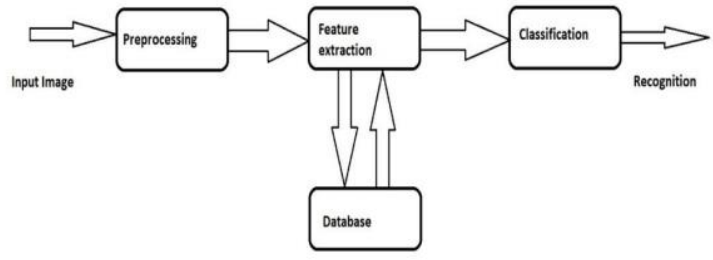

Fig 1.1: Typical face recognition system

\section{LITERATURE SURVEY}

In this paper [1] door access system by using face recognition the images are stored in a database. This system is used for door lock access for Residential and Commercial Purposes. Here they have designed a highly secured door locking system by using Raspberry pi. In this paper

[2] A facial recognition system using raspberry pi can make the system a little lighter and work properly utilizing lower control use, so it is more appropriate than the computer- based facial recognition system. It is open-source software on Linux. they are also providing power backup for the smooth and continuous functioning of the system in case of power failure. For charge the Raspberry Pi they used a power bank so that few possibilities to slow down the system.

According to this paper [3] the system can be used in several places like offices, laboratories and other worldly automated systems, which reduce the probability of problems. Indicate the security department if any issue occurs. 
[4] The paper suggests that the face detection process under controlled lighting conditions (fluorescent light) gives an accuracy of $95 \%$ with scale increase rate at 1.2 , minimum neighbours threshold at 10 and minimum detection scale at 25X25.In this range the recognition rate is at $85 \%$

\section{METHODOLOGY}

\section{A. System design}

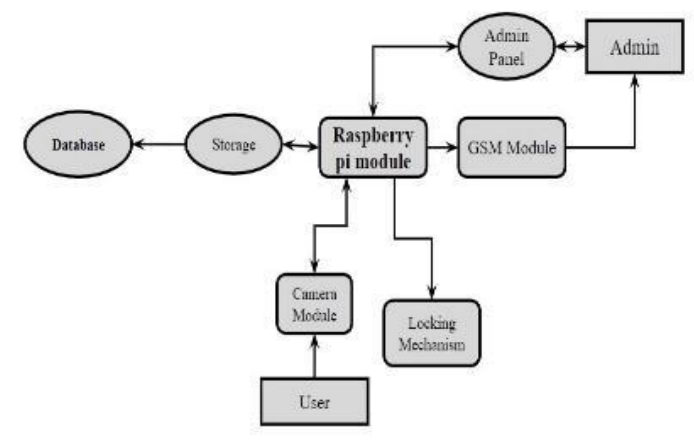

Fig-1.2: Architectural diagram

Face recognition-based door lock system uses a pi camera to capture a video feed and sends it to the raspberry pi for processing and recognition processes. If any face is detected in the frame it will try to recognize it and match it to the database system. After recognizing a person, it will open the lock in the door and will remain locked if detected unknown, and also if any unknown person is detected it will send a message through API to the owner of the system.

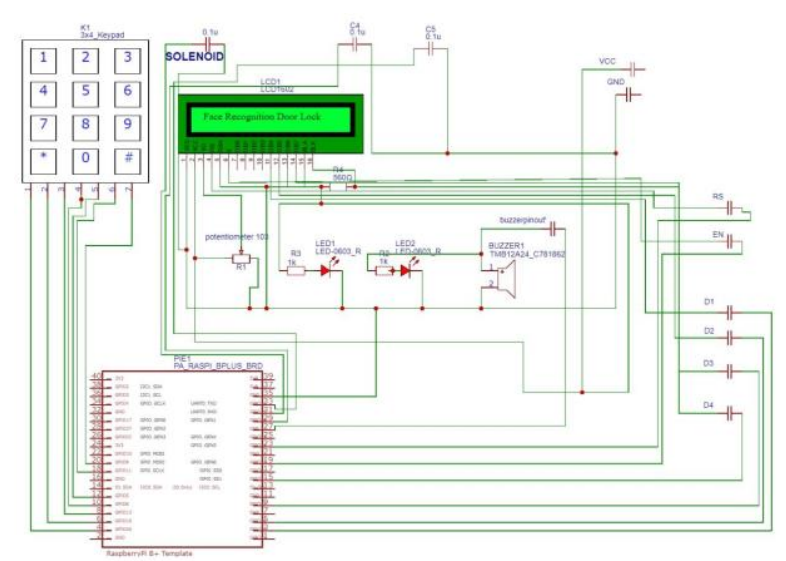

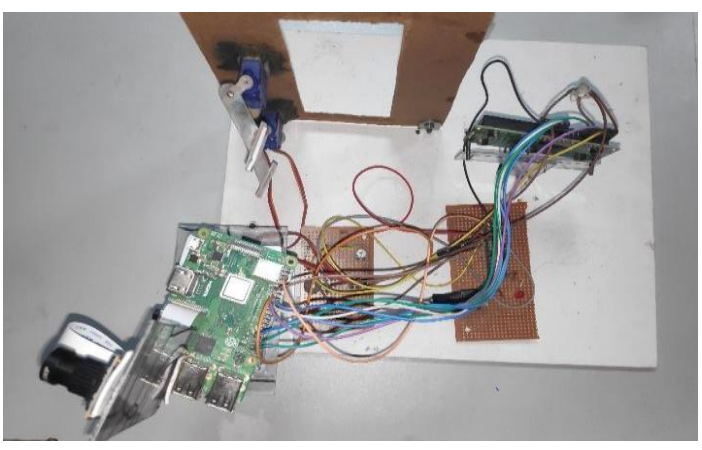

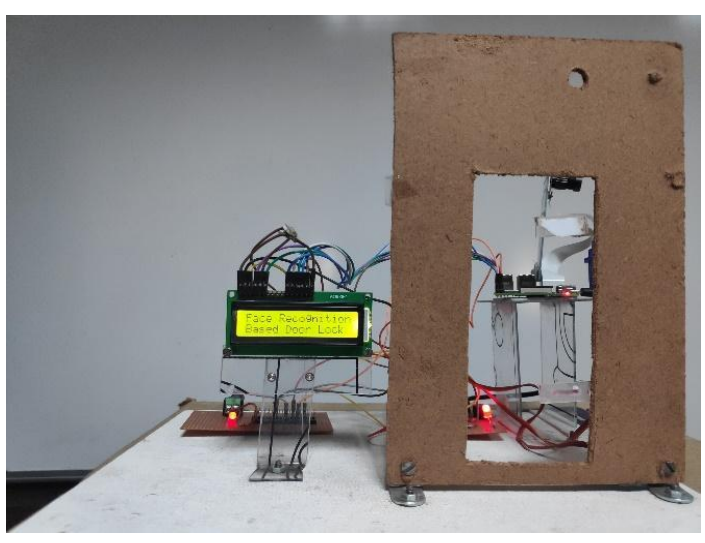

Fig 1.4: Embedded diagram

\section{B. Algorithm used:}

\section{Local Binary Pattern Histogram}

Local Binary Pattern (LBP) is a simple yet very efficient texture operator which labels the pixels of an image by thresholding the neighbourhood of each pixel and considers the result as a binary number. The following steps can define LBPH -------

We have an image having dimensions $\mathrm{N} \mathrm{x} \mathrm{M}$.

We divide it into regions of same height and width resulting in $\mathrm{m} \times \mathrm{m}$ dimension for every region.

Local binary operator is used for every region. The LBP operator is defined in window of $3 \times 3$

$$
\operatorname{LBP}\left(x_{c}, y_{c}\right)=\sum_{p=0}^{p-1} 2^{p} s\left(i_{p}-i_{c}\right)
$$

Fig-1.3: Circuit diagram 
here '(Xc, Yc)' is a central pixel with intensity 'Ic'. And 'In' being the intensity of the neighbour's pixel Using median pixel value as threshold, it compares a pixel to its 8 closest pixels using this function.

$$
s(x)=\{1, x \geq 0, x<00\}
$$

If the value of neighbour is greater than or equal to the central value it is set as 1 otherwise it is set as 0 . Thus, we obtain a total of 8 binary values from the 8 neighbours. After combining these values, we get a 8 bit binary number which is translated to decimal number for our convenience. This decimal number is called the pixel LBP value and its range is 0-255.

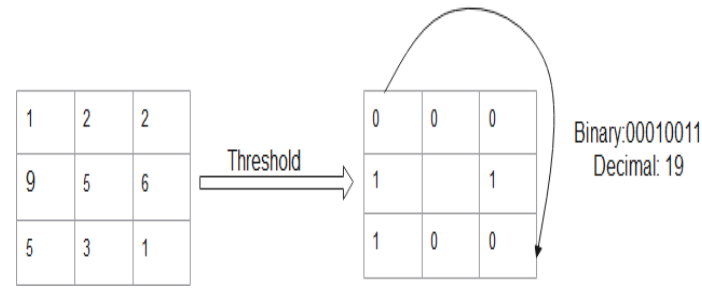

Later it was noted that a fixed neighbourhood fails to encode details varying in scale. The algorithm was improved to use different number of radius and neighbours, now it was known as circular LBP.

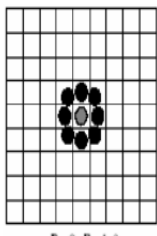

$P=8, R=1.0$

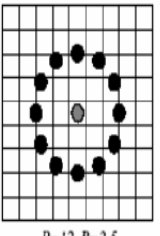

$P=12 R=2.5$

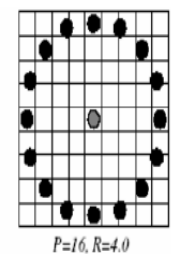

The idea here is to align an arbitrary number of neighbours on a circle with a variable radius. This way the following neighbourhoods are captured:

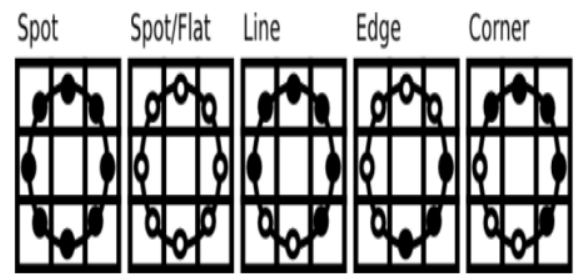

For a given point $(\mathrm{Xc}, \mathrm{Yc})$ the position of the neighbour (Xp, Yp), $\mathrm{p}$ belonging to $\mathrm{P}$ can be calculated by:

$Y_{P}=Y_{C}+R \sin \sin \left(\frac{2 \pi \rho}{\rho}\right)$

$$
X_{P}=X_{C}+R \cos \cos \left(\frac{2 \pi \rho}{\rho}\right)
$$

Here $\mathrm{R}$ is radius of the circle and $\mathrm{P}$ is the number of sample points. If a point's coordinate on the circle doesn't correspond to image coordinates, it gets interpolated generally by bilinear interpolation:

$f(x, y) \approx[1-$

$\begin{array}{ll}x & x][f(0,0) f(0,1) f(1,0) f(1,1)][1-y y]\end{array}$

The Euclidean distance is calculated by comparing the test image features with features stored in the dataset. The minimum distance between test and original image gives the matching rate.

$$
d(a, b)=\left.\sqrt{\sum_{i=1}^{n} \quad \mid a_{i}-} b_{i}\right|^{2}
$$
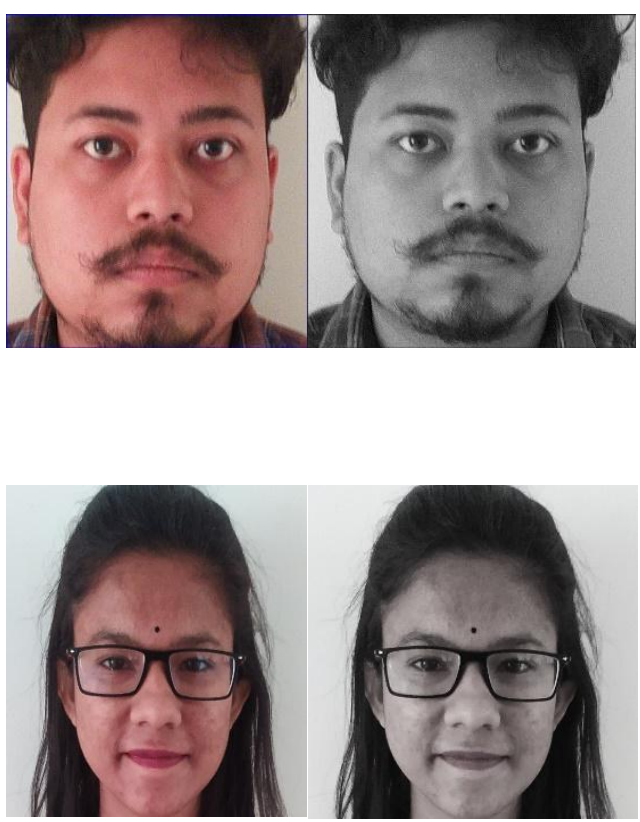

Fig 1.5: Input images used in algorithms

As an output we get an ID of the image from the database if the test image is recognised. 


\section{International Journal of Engineering Applied Sciences and Technology, 2021 \\ Vol. 6, Issue 3, ISSN No. 2455-2143, Pages 294-297 \\ Published Online July 2021 in IJEAST (http://www.ijeast.com)}
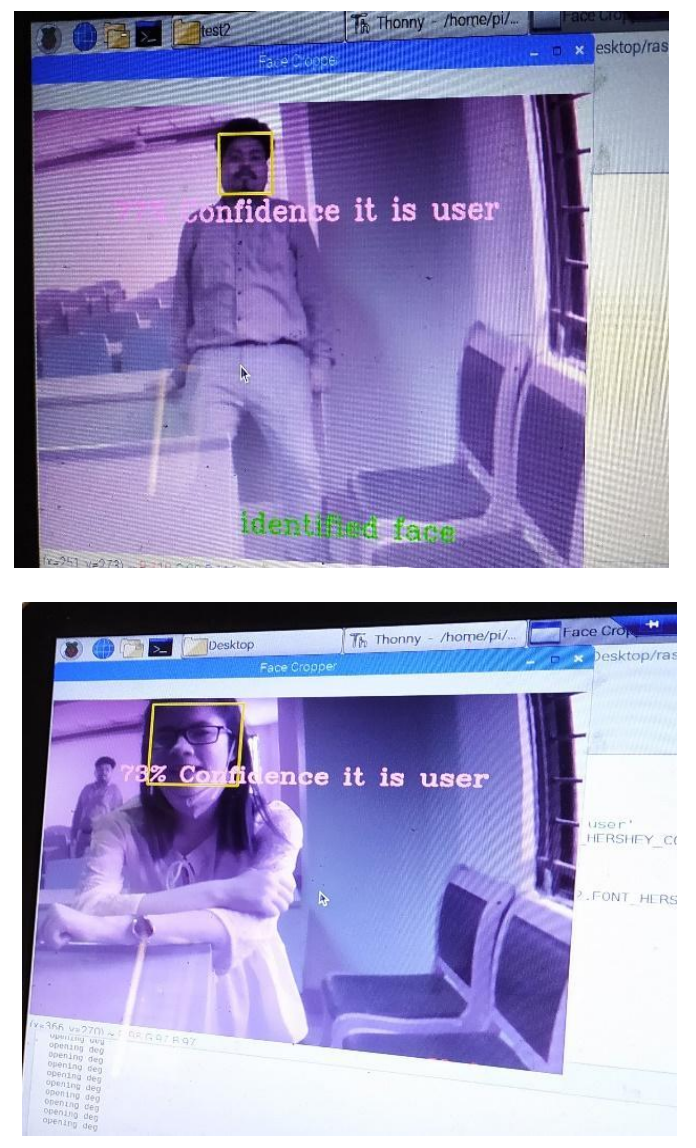

Fig 1.6: Face detection using LBPH

LBPH can recognise both side and front faces and it is not affected by illumination variations which mean that it is more flexible.

\section{TESTING RESULTS}

Table 1: result using LBPH

\begin{tabular}{|l|l|l|l|l|l|}
\hline TEST NO & DATASET & TIMES & POSITIVE & NIGATIVE & ACCURACY \\
\hline 1 & $\begin{array}{l}114 \\
(3 \mathrm{Member})\end{array}$ & 20 times & 15 times & 5 times & $75 \%$ \\
\hline 2 & $\begin{array}{l}209 \\
(6 \mathrm{Member})\end{array}$ & 20 times & 14 times & 6 times & $70 \%$ \\
\hline 3 & $\begin{array}{l}436 \\
(11 \\
\text { Member })\end{array}$ & 20 times & 11 times & 9 times & $55 \%$ \\
\hline 4 & $\begin{array}{l}554 \\
(13 \\
\text { Member })\end{array}$ & 20 times & 12 times & 8 times & $60 \%$ \\
\hline
\end{tabular}

\section{CONCLUSION}

From the testing results it is clear that while dealing with more number of data accuracy of LBPH can decrease. Although LBPH can deal with different light conditions and different poses and effective in detecting faces and recognizing them, so it is chosen as a go to algorithm in face recognition-based door lock system.

\section{FUTURE SCOPE}

In future the system can be deployed in the cloud for easy computational tasks, or some new facial recognition algorithms can be deployed. Alternate recognition measures can also be implemented in the future.

\section{REFERENCES}

[1] "face recognition-based door unlocking system using raspberry pi" Thulluri Krishna Vamsi, Kanchana Charan Sai, Vijayalakshmi M. from SRM Institute of Science and Technology, Chennai, Tamil Nadu. ISSN: 2454-132X Impact factor: 4.295 (Volume 5, Issue 2)

[2]"Iot based door lock and unlock system using face recognition" Rajat Bhise, Nikilesh Phadnis, Rahul Bari, Vijay Dhage (Former Students of K.B.C. North Maharashtra University Jalgaon) Volume: 05, Issue: 12 | Dec 2018 e-ISSN: 2395-0056 p-ISSN: 23950072

[3]"face recognition-based access control of door and home security system" P. Shireesha, M. Tech student, G. Govind, Associate professor, Dr. S. Vathsal, Professor, Dept of EEE, ECE Joginpally B.R. Engineering College, JNTUH, Telangana, India (Volume 4 Issue 5 ISSN: 2349-6002)

[4] "face recognition-based door lock system using OpenCV and C\# with remote access and security features" Prathamesh Timse, Pranav Aggarwal, Prakhar Sinha, Neel Vora, Student, Department of Electronics and Telecommunication Engineering, K.J Somaiya College Of Engineering, Vidyanagar, Vidyavihar(E), Mumbai - 400 077, Maharashtra, India. 